\title{
Numerical simulation of a composite shell for underwater application using CFD and FEA
}

\author{
Pidathala Siva ${ }^{1}$, Vallabhaneni Balakrishna Murthy ${ }^{2, *}$ \\ ${ }^{1}$ PG Scholar, Department of Mechanical Engineering, V. R. Siddhartha Engineering College, Vijayawada, India \\ ${ }^{2}$ Professor, Department of Mechanical Engineering, V. R. Siddhartha Engineering College, Vijayawada, India
}

\begin{abstract}
In the present investigation, an attempt has been made to use fiber-reinforced composite material in place of metal for a shell used for underwater applications which is majorly subjected to hydro-static pressure. The study comprises the use of popular numerical techniques such as finite volume and finite element methods. CFD tool 'ANSYS fluent' which works based on finite volume method is used for the fluid flow simulation to get the forces acting on the structure. Structural analysis is performed for the imported loads from CFD result onto the structure with one-way fluid-structure coupling. FEM tool 'ANSYS static structural which works based on finite element method is used for obtaining deformations and stresses in the shell. A sufficient number of iterations are made to get convergence of the numerical solution. Alternatives such as increasing the shell thickness and/or providing stiffeners to the shell are suggested to replace the metallic structure with FRP composites.
\end{abstract}

\section{Introduction}

Underwater shell structures are mainly subjected to external pressure. The major component of external pressure is hydro-static pressure that depends on the depth of the structure from the free surface of the water. The second component is due to the reaction of fluid on the structure during its motion in water. Shells are, in general, cylindrical with flat or curved closures. One of the typical underwater shells is a torpedo. Torpedoes are provided with self-propeller that operate underwater. Hence to design this kind of underwater shell structure, it is necessary to consider all possible loads and need to ascertain the ability of the structure in terms of strength, stiffness, and buckling resistance. Weight and noise reduction are the major requirements of underwater structures. Fiber-reinforced composite materials are used to minimize the weight and noise levels for underwater applications. The mechanics part of a composite structure is similar to a metallic one but it is required to consider the anisotropic nature of composite materials which is due to their directional dependent material properties while designing a structure with composites.

Edward et al. [1] modeled a conceptual super cavitating torpedo for satisfying the design parameters. Performed multi-disciplinary optimization of the considered models. Design parameters include several stiffeners, stiffener dimensions, and thickness of shell structure.

Vijaya and Gokhale [2] developed aluminum alloy cylindrical shells for advanced torpedo applications. Manufacturing defects identified in the initial trials were rectified by modifying manufacturing procedures.
Observed that the heat-treated and machined components met the required standards.

Edward et al. [3] presented an algorithm for an optimal configuration of the torpedo. They formulated for the general shape of the torpedo that satisfies the performance measures. They have shown a way of optimizing stiffeners in the structure.

Rajesh et al. [4] solved a multidisciplinary optimization problem to design a torpedo with metallic and composite materials and subjected it to underwater explosions. Observed that for underwater explosion loads, the composite torpedo model exhibits better specific strength than the metallic design.

Rajesh et al. [5] investigated the performance of lighter torpedos by introducing the stiffeners. Fluidstructure interaction was simulated in a FE software ABAQUS. They realized that the torpedo with stiffeners showed better results compared to the unstiffened one. Extended the study to optimize the number of longitudinal and ring stiffeners.

Li Nan and Zhao Yun Peng [6] used UG and other open CAD tools for the parametric design of torpedo that facilitates adaptive kind of design and there is no need to repeat the design process for any change in the design parameters.

Li et al. [7] performed a fluid-structure interaction analysis of a torpedo shell structure. They used Fluent software to compute external load on the shell due to the interaction with flowing fluid. They performed a structural analysis in ANSYS software by importing interface loads from the fluid analysis.

Wang et al. [8] applied the previously proposed gradient smoothing method (GSM) for solving a fluid-

\footnotetext{
* Corresponding author: author@e-mail.org
} 
structure interaction (FSI) problem with a rigid structure. A combination of GSM and arbitrary LagrangianEulerian (ALE) methods was applied to solve an FSI problem with moving structure.

Zhang et al. [9] solved a 3-D FSI problem using immersed smoothed finite element method with fournode tetrahedral elements. Observed that, when compared to previous works, their method showed better stability of the second-order spatial convergence scheme.

Matthew and Roberto [10] developed, evaluated, and validated the finite element analysis using ANSYS software for the simulation of the impact of a torpedo on a submarine hull. Verified the numerical results from geometrical and material nonlinear analyses with experimental test data and found that numerical results in the case of a concentrated load are not matching with experimental data.

Lin and Kuei [11] studied the influence of various operating conditions on the performance of a Markov type of torpedo. Their method uses six states for representing the dynamic performance of torpedo and submarine. They showed exponential deterioration of the performance of torpedo for several countermeasures.

Ramesh and Yogesh [12] analyzed homing headshell of a torpedo. They prepared various configurations of the homing head-shell and made a comparative study before finalizing the design.

Myungjun et al. [13] calculated the dynamic response using the chain rule of partial sensitivity. Results of their sensitivity analysis were used to obtain the optimum design of an underwater vehicle.

Pothurajuet al. [14] performed a static analysis of a torpedo using the finite element method. The response of the structure was predicted by varying design parameters such as material properties, loading conditions, and boundary condition to optimize the design. Concluded that Atlas exhibits better performance when compared with other models.

Pothurajuet al. [15] performed finite element analysis on an Atlas torpedo subjected to shock load. They used CATIA software for the solid model of the problem and carried out the analysis part in ANSYS software. The static response was obtained for variation in the design parameters. Later they extended the study to evaluate the linear buckling response of the torpedo.

Surya and Ramajeyathilagam [16] analyzed ring stiffened cylindrical shells subjected to shock load. Fluid-structure interaction including geometric and material nonlinear effects was simulated in LS-DYNA software. The numerical results were compared with experimental results and found within 5\% accuracy. Extended the study for parametric investigation.

Observations from the review of literature motivated the authors to take up the problem of replacing the existing metallic shell used for underwater applications with a composite shell to explore the issues that arise in the processes of replacement and the ways to correct the situation.

\section{Problem modeling}

\subsection{Geometrical Modeling}

The torpedo-like underwater shell structure is considered for the present analysis. Fig. 1 shows the two domains for the shell and fluid flow. The diameter, length, and thickness of the shell are $0.5 \mathrm{~m}, 7 \mathrm{~m}$, and $0.025 \mathrm{~m}$ respectively. The length of the cylindrical portion is $6 \mathrm{~m}$. A hemispherical dome of $0.25 \mathrm{~m}$ radius at the front and elliptical dome of $0.25 \mathrm{~m}$ maximum radius and $0.75 \mathrm{~m}$ length at back are used to close the shell. A fluid enclosure of $9.75 \mathrm{~m}$ in length and $2.5 \mathrm{~m}$ in diameter is provided. Solids for both shell and fluid domain are generated by rotating the two-dimensional sketches through an angle of $30^{\circ}$.

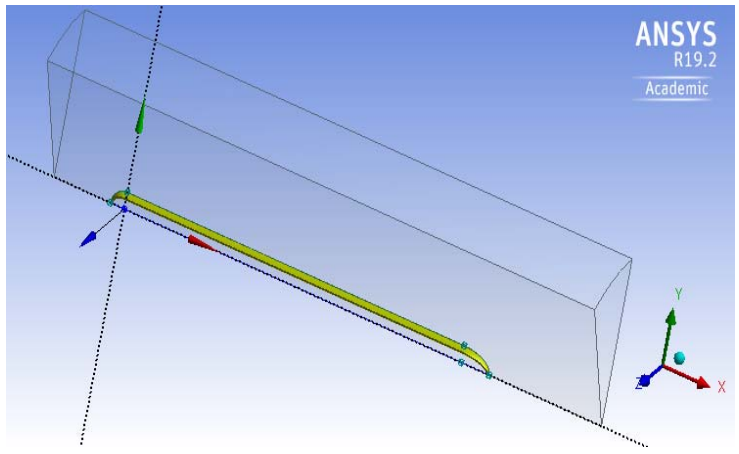

Fig. 1 Shell generated from the outer surface of solid

\subsection{Numerical Modelling for fluid flow}

Fig. 2 shows the nomenclature used for the fluid analysis. Label ' $A$ ' is the inlet, where the velocity and operating conditions of the fluid can be specified. Label ' $\mathrm{B}$ ' represents the far-field symmetry condition. ' $\mathrm{D}$ ' is the outlet. Labels ' $C$ ' and ' $E$ ' are meant for assigning symmetry conditions to constrain the fluid motion in the tangential direction at these faces. Label ' $F$ ' is the solid interface, where no-slip wall condition can be given.

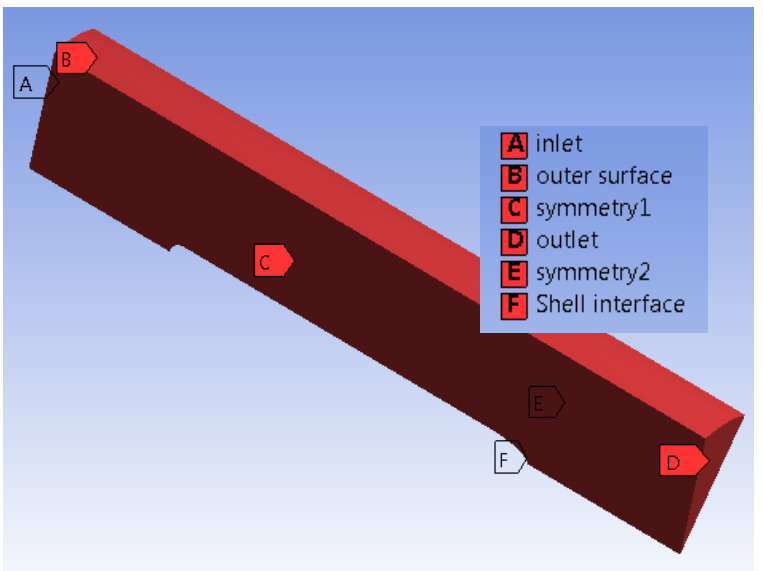

Fig. 2 Named selections in the fluid domain

Global and local Mesh controls used for the generation of mesh in the fluid domain are listed in 
Tables 1 and 2. Fig. 3 shows the mesh generated in the fluid domain. Inflation layers at the shell interface are shown in Fig. 4. Spalart-Allmaras model is considered for turbulent conditions. Water with density $=1000$ $\mathrm{kg} / \mathrm{m}^{3}$ and viscosity $0.001 \mathrm{~kg} /(\mathrm{m}-\mathrm{s})$ is taken as the fluid. Operating pressure of $6 \mathrm{MPa}$ corresponding to $600 \mathrm{~m}$ depth of water is considered. The velocity of the fluid at the inlet is taken as $10 \mathrm{~m} / \mathrm{s}$.

Table 1. General mesh controls

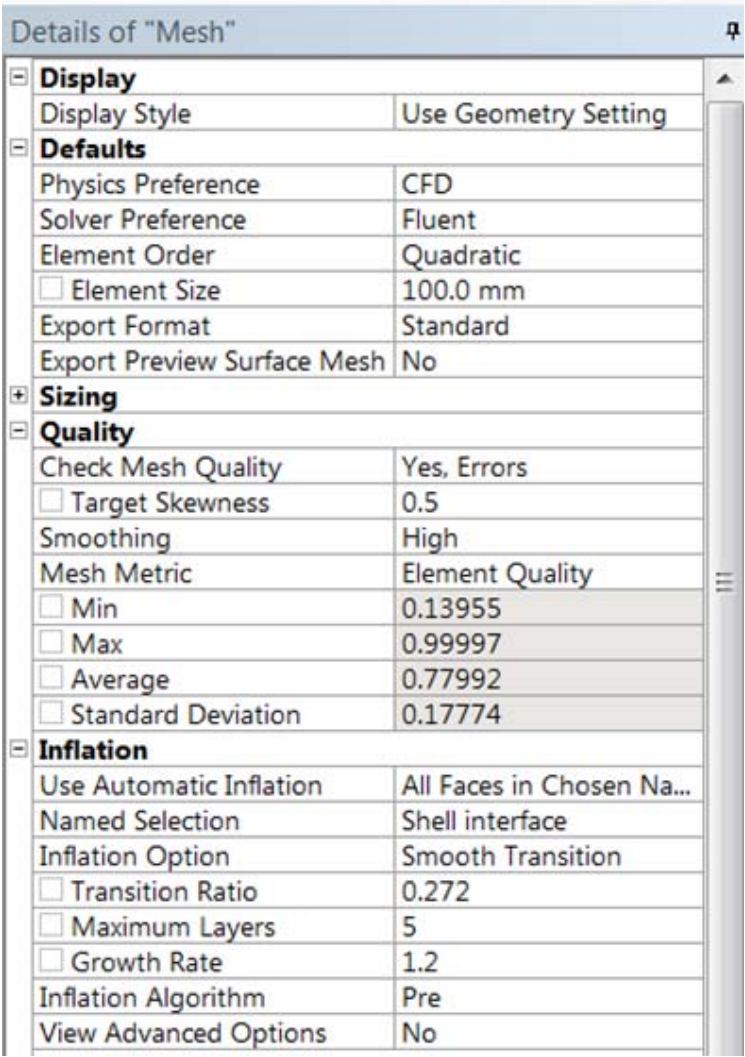

Table 2. Mesh controls at shell interface

Details of "Face Sizing" - Sizing
\begin{tabular}{|l|l|}
\hline Scope & \multicolumn{1}{l|}{} \\
\hline Scoping Method & Named Selection \\
\hline Named Selection & Shell interface \\
\hline Definition & No \\
\hline Suppressed & Element Size \\
\hline Type & $20.0 \mathrm{~mm}$ \\
\hline$\square$ Element Size & \\
\hline Advanced & Default $(0.5 \mathrm{~mm})$ \\
\hline$\square$ Defeature Size & Default $(1.2)$ \\
\hline$\square$ Growth Rate & Yes \\
\hline Capture Curvature & Default $\left(18.0^{\circ}\right)$ \\
\hline$\square$ Curvature Normal Angle & Default $(1.0 \mathrm{~mm})$ \\
\hline$\square$ Local Min Size & Yes \\
\hline Capture Proximity & Default $(1.0 \mathrm{~mm})$ \\
\hline$\square$ Proximity Min Size & Default $(3)$ \\
\hline$\square$ Num Cells Across Gap & Faces and Edges \\
\hline Proximity Size Function Sources & F \\
\hline
\end{tabular}

The symmetry boundary condition is imposed on the outer surface and circumferential faces of the fluid domain to ensure that the flow is only tangential. The fluid solution is converged at the $500^{\text {th }}$ iteration. The results of the fluid analysis are transferred to static structural analysis to consider the interface pressure as the distributed load on the shell.

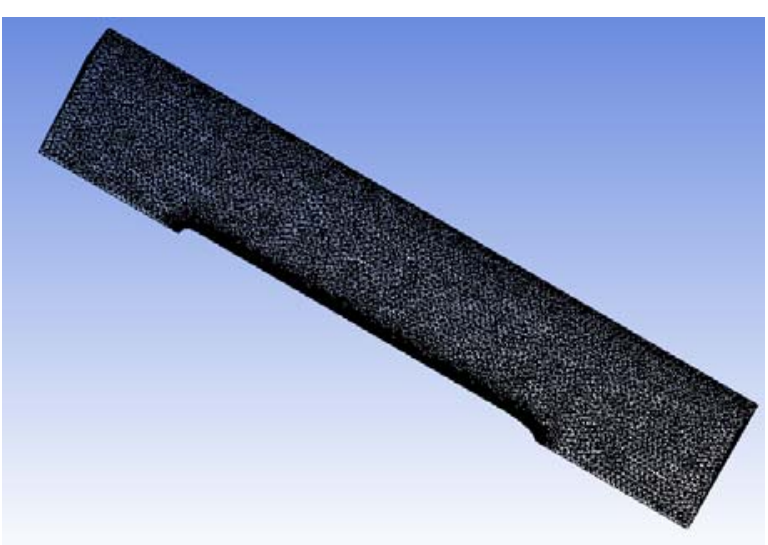

Fig. 3 Mesh in the fluid domain

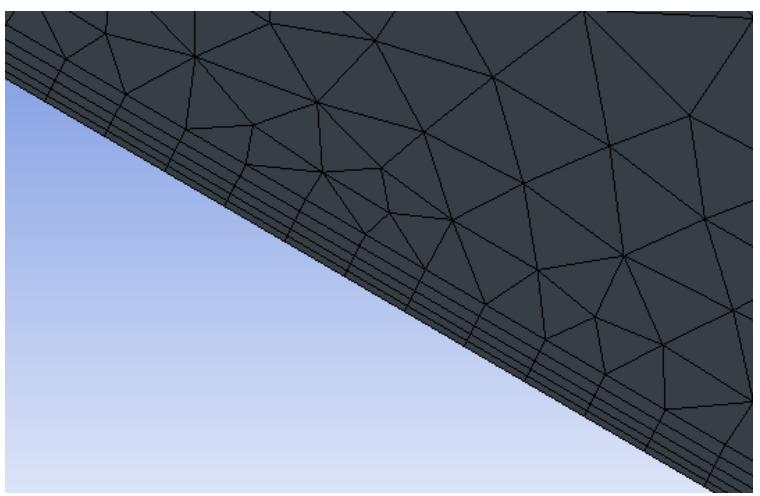

Fig. 4 Inflation layers at shell interface in the fluid domain

Aluminum alloy with $\mathrm{E}=71 \mathrm{e} 9 \mathrm{~N} / \mathrm{m}^{2}$ and Poisson's ratio of 0.33 is assigned to the metallic shell. Threedimensional quadratic elements of $0.020 \mathrm{~m}, 0.015 \mathrm{~m}$, and $0.010 \mathrm{~m}$ one at a time are used to create a mesh in the solid domain for convergence study. Fig. 5 shows the imported pressure from fluid analysis through one-way coupling. It can be observed that variation of pressure is negligibly small indicating that hydrostatic pressure is the major one. Table 3 presents the total deformation and equivalent stress in the Aluminium shell for three different finite element meshes. Total deformation and equivalent stress are observed to be almost equal for all three sizes of the element considered. Further analysis can be taken up with any of these three cases. 


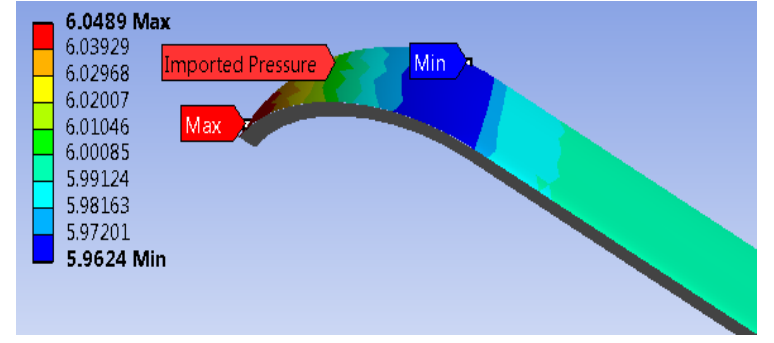

Fig. 5 Imported pressure (MPa)

Table 3. Structural results with the change in element size

\begin{tabular}{|c|c|c|}
\hline $\begin{array}{c}\text { Element size } \\
(\mathrm{m})\end{array}$ & $\begin{array}{c}\text { Total } \\
\text { deformation } \\
(\mathrm{m})\end{array}$ & $\begin{array}{c}\text { Equivalent } \\
\text { stress }\left(\mathrm{N} / \mathrm{m}^{2}\right)\end{array}$ \\
\hline 0.020 & 0.0010339 & $55.24 \mathrm{E} 6$ \\
\hline 0.015 & 0.001034 & $55.22 \mathrm{E} 6$ \\
\hline 0.010 & 0.001034 & $55.21 \mathrm{E} 6$ \\
\hline
\end{tabular}

\section{Metallic vs composite shell}

Modeling of carbon fiber composite shell for similar operating conditions considered as in the case of the metallic shell is presented in this section. Static response of the composite shell under hydrodynamic loads transferred from fluid analysis through one-way coupling is compared with an Aluminum shell of the same thickness. Modifications in the design of composite shell to maintain the stiffness equivalent to that of metallic one are suggested.

The solid modeling of a composite shell is different from that of a metallic shell. In the geometry tool, the interface area is converted to a surface body, and this surface is transferred to the ANSYS composite pre-post tool, where the required thickness will be built up with the lamination sequence. A unidirectional carbon-epoxy composite material, which is designated as Epoxy Carbon UD (230GPa) Prepreg in ANSYS software is considered for the present analysis. Mechanical properties of this material are provided in Table 4.
Table 4 Carbon Epoxy UD (230GPa) properties

\begin{tabular}{|c|c|c|c|}
\hline \multicolumn{3}{|c|}{ Properties of Outine Row 4: Epoxy Carbon UD (230 GPa) Prepreg } & \\
\hline & A & B & \\
\hline 1 & Property & Value & \\
\hline 2 & 7 Density & 1490 & $\mathrm{~kg} \mathrm{~m} \wedge-3$ \\
\hline 3 & 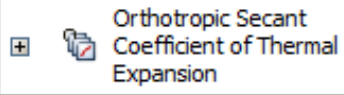 & & \\
\hline 8 & $\square$ Orthotropic Elasticity & & \\
\hline 9 & $\begin{array}{l}\text { Young's Modulus X } \\
\text { direction }\end{array}$ & $1.21 \mathrm{E}+05$ & $\mathrm{MPa}$ \\
\hline 10 & $\begin{array}{l}\text { Young's Modulus Y } \\
\text { direction }\end{array}$ & 8600 & $\mathrm{MPa}$ \\
\hline 11 & $\begin{array}{l}\text { Young's Modulus Z } \\
\text { direction }\end{array}$ & 8600 & MPa \\
\hline 12 & Poisson's Ratio XY & 0.27 & \\
\hline 13 & Poisson's Ratio YZ & 0.4 & \\
\hline 14 & Poisson's Ratio XZ & 0.27 & \\
\hline 15 & Shear Modulus XY & 4700 & $\mathrm{MPa}$ \\
\hline 16 & Shear Modulus YZ & 3100 & MPa \\
\hline 17 & Shear Modulus XZ & 4700 & MPa \\
\hline
\end{tabular}

In the present case, the required thickness of $0.025 \mathrm{~m}$ is obtained by placing 10 layers of $0.0025 \mathrm{~m}$ thick each symmetrically as 0/90/90/0/0/0/0/90/90/0. Boundary conditions imposed in metallic shell are considered in this case also.

\subsection{Analysis of results}

Table 5 shows the deformation of composite and metallic shells. By comparing composite shell results with metallic one, we can observe that the deformations in composite shell are very high compared to metallic shell. This is due to the directional-dependent properties of the composite.

Table 5. Deformations in metallic and composite shells

\begin{tabular}{|c|c|c|c|}
\hline Material & $\begin{array}{c}\text { Total } \\
\text { deformation } \\
(\mathrm{m})\end{array}$ & $\begin{array}{c}\text { Radial } \\
\text { Deformation } \\
(\mathrm{m})\end{array}$ & $\begin{array}{c}\text { Axial } \\
\text { Deformation } \\
(\mathrm{m})\end{array}$ \\
\hline Aluminium & 0.001034 & -0.000170 & -0.001034 \\
\hline CFRP & 0.001938 & -0.000352 & -0.001923 \\
\hline
\end{tabular}

\subsection{Modifications in composite shell}

Two alternative modifications are made in the composite shell to improve its stiffness. In the first case, the shell thickness is doubled and in the second case without changing the shell thickness, stiffeners are provided to the shell. Ring stiffeners of $w=0.010 \mathrm{~m}, \mathrm{t}=0.025 \mathrm{~m}$, at $0.5 \mathrm{~m}$ spacing, and Axial stiffeners of $\mathrm{w}=5^{0}$ angle, $\mathrm{t}=0.025 \mathrm{~m}$, at $30^{\circ}$ angular spacing are provided to composite shell of $0.025 \mathrm{~m}$ thickness. Table 6 displays the comparison of these results. From the results, it can be observed that axial deformation is close to total 
deformation indicating that the radial deformation is negligible. From any one of the alternative methods, it is possible to obtain the required stiffness in the composite shell equivalent to that of the metallic shell.

Table 6. Comparison of modified composite shell results

\begin{tabular}{|c|c|c|c|}
\hline Material & $\begin{array}{c}\text { Total } \\
\text { deformation } \\
(\mathrm{m})\end{array}$ & $\begin{array}{c}\text { Radial } \\
\text { Deformation } \\
(\mathrm{m})\end{array}$ & $\begin{array}{c}\text { Axial } \\
\text { Deformation } \\
(\mathrm{m})\end{array}$ \\
\hline $\begin{array}{c}\text { Aluminium } \\
(\mathrm{t}=0.025 \mathrm{~m})\end{array}$ & 0.001034 & -0.000170 & -0.001034 \\
\hline $\begin{array}{c}\text { CFRP } \\
(\mathrm{t}=0.025 \mathrm{~m})\end{array}$ & 0.001938 & -0.000352 & -0.001923 \\
\hline $\begin{array}{c}\text { CFRP } \\
(\mathrm{t}=0.050 \mathrm{~m})\end{array}$ & 0.000966 & -0.000162 & -0.000960 \\
\hline $\begin{array}{c}\text { CFRP } \\
\mathrm{t}=0.025 \mathrm{~m} \\
+ \\
\text { Stiffeners })\end{array}$ & 0.000936 & -0.000254 & -0.000904 \\
\hline \multicolumn{2}{|l}{} & & \\
\hline
\end{tabular}

\section{Conclusions}

Numerical simulation of an underwater shell structure is performed using CFD and FEM modules of ANSYS software. The major concern of the work is to explore the possibility of replacing an existing metallic shell with a fiber-reinforced composite shell. Following conclusions are drawn from the present analysis.

- Pressure variation due to water flow is negligibly small when compared to hydrostatic pressure at $600 \mathrm{~m}$ depth.

- Deformations in carbon-epoxy composite considered in this study are very high compared to Aluminium shell of the same thickness.

- The composite shell can be modified by doubling the thickness or providing Aluminium stiffeners to the composite shell of $0.025 \mathrm{~m}$ thick to improve the structural stiffness of the composite shell.

\section{References}

1. E. Alyanak, V. Venkayya, R. Grandhi, R. Penmetsa, Finite Elem. Anal. Des. 41, 563 (2005).

2. V. Singh and A.A. Gokhale, Def. Sci. J. 55, 83 (2005).

3. E. Alyanak, R. Grandhi, and R.i Penmetsa, Int. J. Solids Struct. 43, 642 (2006).

4. R. Kalavalapally, R. Penmetsa, and R. Grandhi, Finite Elem. Anal. Des. 43, 103 (2006).

5. R. Kalavalapally, R. Penmetsa, and R. Grandhi, Int. J. Impact Eng. 36, 343 (2009).

6. N. Li and Y. P. Zhao, N. Li and Y. P. Zhao, Adv. Mat. Res. 542, 532 (2012).

7. N. Li, B. W. Song and K. Wei, Appl. Mech. Mater. 256, 2844 (2013).

8. S. Wang, B.C. Khoo, G.R. Liu, and G.X. Xu, Comput. Fluids 71, 327 (2013).

9. Zhang, Zhi-Qian, G. R. Liu, and B. Cheong Khoo. Comput Mech. 51, 129 (2013).
10. M. Chatterton, and R. Ojeda, Ocean Eng. 82, 128 (2014).

11. L. Hui, and K.M. Wang, Expert Syst. Appl. 42, 9129 (2015).

12. J.V.R. Ramesh, and K. Yogesh, Int. j. res. appl. sci. eng. technol. 5, 771 (2017).

13. M. Jeon, H.K. Yoon, J. Hwang, and H.J. Cho, Int. J. Nav. Archit. Ocean Eng. 10, 508 (2018).

14. P.V.V. Satyanarayana, A.V. Krishna, Int. Res. J. Eng. Technol. 5, 1303 (2018).

15. P.V.V. Satyanarayana, K.J. Rani, P. Satya Lakshmi, and M. Murali Krishna, Int. Res. J. Eng. Technol. 5, 580 (2018).

16. R.P.S. Praba and K. Ramajeyathilagam, Appl. Ocean Res. 101, 102262 (2020).

17. ANSYS reference Manuals (2020). 